\title{
Macroprudential Ideas and Auxiliary Change in Financial Governance Paradigm
}

\begin{abstract}
Jaehwan Jung
Since the global financial crisis of 2008 , some have referred to the macroprudential turn in global financial governance as a paradigm shift. However, this article argues that macroprudential ideas cannot be seen as a paradigm shift since macroprudential regulation supplements, rather than replaces, existing microprudential regulation. In this respect, it is more precise to conceptualize the macroprudential turn as "auxiliary change," which means an incremental change brought about by adding auxiliary hypotheses while maintaining the hard-core assumptions of the existing policy paradigm. The hardcore assumptions of the financial governance paradigm are its ontology and epistemology, which stipulate what entities constitute financial markets and how actors understand the financial world surrounding them. Macroprudential ideas have not changed the core ontological and epistemological assumptions of microprudential ideas, that is, individualistic ontology and rationalistic epistemology. Rather, they have introduced auxiliary hypotheses, such as a fallacy of composition and bounded rationality, into the financial governance paradigm to explain a newly identified anomaly, namely, systemic risk. Diametrically opposed to the orthodox paradigm in terms of ontology and epistemology is what can be called "social constructivist ideas," which are founded on sociological ontology and epistemology.
\end{abstract}

Key Words: financial governance, macroprudential regulation, paradigm change, auxiliary change, social constructivism

$\mathrm{T}$ he global financial crisis of 2008 can be seen as a "natural experiment to test the efficient-market theory," as the crisis started with "the least regulated and most competitive parts of the financial market” (Wade 2008, 34). As a result,

*Jaehwan Jung (jaehwan21@gmail.com) is a visiting professor at Incheon National University. He received a Ph.D. in politics and international studies from the University of Cambridge. His research interests include the politics of international finance, constructivist political economy, and the Korean political economy. 
it was widely expected that the crisis would lead to "fundamental ontological and epistemological shifts" in the financial governance paradigm (Best 2016, 48). Several scholars have argued that, in the words of Mackintosh (2014, 406), "a paradigm shift in financial and regulatory ideology is underway" and that at the heart of such a paradigm shift is the emergence of macroprudential ideas in global financial governance. Macroprudential ideas, which are referred to as, in the words of Haldane (2009), "a new ideology and a big idea," focus on the financial system as whole, rather than individual institutions, with the aim of identifying, monitoring and addressing systemic risk. According to Baker (2013b, 420-421), since the 2008 crisis, the center of global financial governance has changed from "an efficient markets consensus to a macroprudential consensus."

This article argues that the emergence of macroprudential ideas in global financial governance cannot be seen as a paradigm shift, owing to the role, as described by Thomas Khun (1962), of "incommensurability" in explaining paradigm shifts. The incommensurability thesis means that different paradigms are not only incompatible but also incommensurable because of their distinct problematiques and concepts. However, most proponents of macroprudential ideas see the relationship between macroprudential and microprudential regulations as complementary rather than incompatible and/or incommensurable. It frequently has been noted that macroprudential regulation supplements, rather than replaces, existing microprudential regulation. Although they have been referred to as "a new ideology and a big idea," macroprudential ideas do not completely reject the existing policy paradigm, that is, microprudential ideas based on a market efficient hypothesis.

In a fundamental sense, microprudential and macroprudential ideas share the hard-core assumptions of what constitutes financial markets and how they operate. The hard-core assumptions of the global financial governance paradigm are its ontology and epistemology of financial markets, which stipulate what entities constitute financial markets and how economic actors understand the financial world surrounding them. Although macroprudential ideas have changed the primary scale of analysis from a micro-level into a macro- or system-level, they have not abandoned the core ontological and epistemological assumptions of the orthodox paradigm, that is, individualistic ontology and rationalistic epistemology. Rather, they have introduced auxiliary hypotheses, such as a fallacy of composition and bounded rationality, into the existing financial governance paradigm to explain a newly identified anomaly, namely, systemic risk. In other words, while maintaining the core ontological and epistemological assumptions of microprudential ideas, macroprudential ideas add auxiliary conceptual tools to global financial governance in order to fill a regulatory loophole that micro- 
prudential ideas could not have identified.

The role of macroprudential regulation in global financial governance is not to replace existing microprudential regulation but to deal with residual regulatory problems that microprudential regulation could not cover. In this respect, it is more precise to conceptualize the impact of macroprudential ideas on the financial governance paradigm, to use the term of Imre Lakatos (1970), as "auxiliary change," which means an incremental change brought about by adding auxiliary hypotheses while maintaining the hard-core assumptions of the existing policy paradigm, as opposed to a paradigm shift that includes a change in the hardcore assumptions. A paradigm shift in global financial governance should be accompanied by a change in the core ontological and epistemological assumptions of the financial governance paradigm. For instance, as compared to macroprudential ideas, what can be called "social constructivist ideas" are diametrically opposed to microprudential ideas in terms of ontology and epistemology. Social constructivist ideas completely reject the hard-core assumptions of microprudential ideas since they are founded on sociological ontology and epistemology.

The paper is organized as follows. The next two sections explain the macroprudential turn in global financial governance following the 2008 financial crisis and introduce the concept of auxiliary change, as opposed to paradigm shift, to interpret the impact of macroprudential ideas on the financial governance paradigm. The following sections discuss the ontology and epistemology of three different financial governance ideas - microprudential, macroprudential, and social constructivist and their policy implications. The study's conclusions are in the final section.

\section{THE MACROPRUDENTIAL TURN IN GLOBAL FINANCIAL GOVERNANCE}

One of the most important changes in global financial governance following the 2008 financial crisis is the emergence of macroprudential ideas in financial regulatory communities. Since the 2008 crisis, the idea of macroprudential regulation has become a new principal interpretive framework for financial technocrats and regulators to diagnose the instability of financial markets and devise regulatory measures to maintain financial stability (Baker 2013a). Macroprudential ideas represent a meaningful change in global financial governance in terms of both the understanding of the root causes of financial instability and regulatory approaches to financial markets. Rejecting the premise that financial markets could be self-regulated by microprudential risk management, macroprudential 
ideas acknowledge that there is endogenous risk that arises as the result of the interactions of individual prudential behaviors (Baker 2010). Macroprudential ideas thus focus on the systemic, rather than individual, risk of financial markets and advocate a top-down approach to the regulation of financial markets (Baker 2013b; Harnay and Scialom 2016).

Prior to the financial crisis of 2008, global financial governance was principally informed by the efficient market hypothesis, the cornerstone of which was that market prices instantaneously reflected all available information and thus the price of securities and their fundamental value were equal, or their difference was economically insignificant given transaction costs. Based on this assumption of efficient market hypothesis, financial governance prior to the 2008 financial crash regarded microprudential ideas, which stressed "greater transparency, more disclosure and more effective risk management by individual institutions," as a principal interpretive framework for governing financial markets (Harnay and Scialom 2016, 403-406). In particular, after the Asian financial crisis of 1997, global financial governance was centered on efforts to develop international financial standards and codes. These efforts were based on the assumption that the central cause of financial crises was a lack of information that market actors could employ to make their decisions and, thus, the supply of adequate information to financial markets would prevent crises. For this purpose, the Financial Stability Forum (FSF) was established in 1999 to facilitate discussion and cooperation for establishing international standards and codes. The International Monetary Fund (IMF) published the Reports on Standards and Codes (ROSCs) to provide financial markets with information regarding which countries adopted standards and codes. It was expected that market actors would be better able to evaluate financial risks by employing this information, thereby promoting financial stability as well as rewarding compliance with standards and codes and punishing failure to meet them (Best 2010; Wade 2007).

Immediately after the financial crash of 2008 , the FSF still seemed to be committed to microprudential ideas by stressing the old trilogy of "greater transparency, more disclosure and more effective risk management" (Best 2010, 32-33). One year later, however, the Horsham G20 communiqué of 2009 publicly endorsed macroprudential ideas by advocating countercyclical capital buffers to mitigate the procyclicality of the financial system. Since then, macroprudential ideas have replaced microprudential ones as the principal framework of financial governance, dominating the policy agenda in the postcrisis financial reform debate and informing many of key proposals from such prominent public authorities as the Basel Committee on Banking Supervision 
(BCBS), the Financial Stability Board (FSB), and national central banks (Baker 2013b). For instance, the Basel III agreement adopted provisions for countercyclical capital buffers as an instrument of macroprudential regulation, and new public authorities for implementing macroprudential regulation have been established in the financial centers of the world, such as the Financial Stability Oversight Council (FSOC) in the United States, the Financial Policy Committee (FPC) in the United Kingdom and the European Systemic Risk Board (ESRB) in the European Union (Baker 2015; Lombardi and Moschella 2017).

As Andrew Crokett, General Manager of the Bank for International Settlements, has put it, macroprudential ideas have different objectives of financial regulation and conceptions of mechanisms influencing financial outcomes from those of microprudential ideas. While microprudential ideas aim to limit the likelihood of failure of individual financial institutions with a focus on the "idiosyncratic risk" of individual institutions, macroprudential ideas put an emphasis on the "systemic risk" of the financial system as a whole with an objective of "limiting the likelihood of the failure, and corresponding costs, of significant portions of the financial system" (Crokett 2000). The focus of macroprudential ideas on systemic risk derives from the acknowledgement that the apparently rational activities of individual financial institutions could cause undesirable instability in the system in the aggregate, and thus financial stability is dependent on "the collective rather than the individual behavior of financial institutions" (Baker 2013a, 115; emphasis original). In other words, macroprudential ideas acknowledge that the risk management of individual institutions is inadequate to maintain the stability of the financial system as a whole because of endogenous risks generated by the result of the collective behavior of financial institutions.

More specifically, macroprudential ideas take seriously the cross-sectional and time dimensions of financial risk in explaining the instability of the financial system. The cross-sectional dimension of financial risk can be interpreted in terms of correlations and common exposures among financial institutions. While microprudential ideas are mainly concerned with risk concentration within individual institutions, macroprudential ideas focus more on similar portfolio holdings among interconnected institutions in the financial system, since the similarity in risk exposure and the balance-sheet linkages across financial institutions increases systemic risk that is larger than the sum of the risks of individual institutions (Datz 2013; Harnay and Scialom 2016). Microprudential ideas are concerned only with individual institutions with a high level of financial risk exposure because they assume that the soundness of the financial system as a whole is equal to the sum of the soundness of individual institutions. In 
contrast, according to macroprudential ideas, if all individual institutions have the same kind of risky assets, it could engender the instability of financial system as a whole regardless of the level of risk exposure of individual institutions because the similarity in risk exposure and the balance-sheet linkages across financial institutions could cause a system-wide deterioration of balance sheets.

In terms of the time dimension of financial risk, macroprudential ideas put an emphasis on the procyclicality of financial markets, which can be explained by the Minsky cycle. According to the Minsky cycle, the tranquility period of financial markets tends to weaken risk perceptions and strengthen optimistic expectations, eventually leading to the booming phase of a financial cycle in which the expansion of liquidity increases asset prices and creates a financial bubble. During the Minsky cycle when financial actors suddenly realize the high degree of exposure to risk, however, demand for low-risk and liquid assets rapidly increases, thereby leading to the contractive phase of the financial cycle in which the contraction of liquidity causes the prices of financial assets to plummet and makes the bubble bust (Frenkel and Rapetti 2009, 687). To alleviate procyclicality and, thus, the boom-and-bust financial cycle, macroprudential ideas stress countercyclical capital buffers which help to reduce liquidity in the booming phase of the financial cycle and increase it in the contractive phase of the cycle.

In sum, while microprudential ideas prior to the 2008 crisis interpreted financial instability as resulting from the excessive risk-taking behaviors of individual financial institutions with a focus on the micro-dynamics of financial markets, macroprudential ideas put an emphasis on "the system" as the primary scale of analysis with an aim to manage the interconnected, complex dynamics of financial markets (Datz 2013, 466-468).

\section{PARADIGM SHIFT OR AUXILIARY CHANGE IN GLOBAL FINANCIAL GOVERNANCE?}

Following Hall's work (1993), some scholars have interpreted "the macroprudential turn" in global financial governance as a paradigm shift. ${ }^{1}$ For instance,

\footnotetext{
${ }^{1}$ Using Kuhn's concept of paradigm shift, Peter Hall $(1993,279)$ provided an analytical framework in which policy change is explained as a change in the policy paradigm, which can be defined as "a framework of ideas and standards that specifies not only the goals of policy and the kind of instruments that can be used to attain them, but also the very nature of the problems they are meant to be addressing."
} 
Baker (2013a, 113) has argued that macroprudential ideas "challenge and reject efficient market theories and advance a quite different conception of market relations and behavior," thereby providing a new understanding of how financial markets work and redefining the role of public authorities and the legitimate activities of private financial actors. According to Baker (2013a, 128), this macroprudential turn in global financial governance fits with a paradigm shift because macroprudential ideas introduce "a completely different and diametrically opposed set of assumptions about how the financial world actually operates" as compared to microprudential ideas, thereby inducing "a substantial change in the hierarchy of policy goals" in financial governance.

Although the emergence of macroprudential ideas has been the most remarkable change in global financial governance following the 2008 crisis, it is still unclear as to what extent macroprudential ideas would lead, or have led, to a profound, paradigmatic change in global financial governance. As Helleiner (2014, 127-128) has noted, "although these ideas offered a critique of the efficient market hypothesis, they backed constraints on markets only insofar as the latter contributed to systemic risk. Because the latter concept was rather vague and hard to identify precisely, its meaning and policy significance were hotly contested." The controversy over the meanings of macroprudential ideas and their potential effects on financial governance have been caused partly by the discursive articulation of the alleged relationship between macroprudential ideas and paradigm shifts. This paper argues that macroprudential ideas cannot be seen as an example of Kuhn's concept of paradigm shift because of the role of "incommensurability" in explaining paradigm shifts. Kuhn used the term "incommensurability" to highlight the holistic nature of paradigm change in a science revolution. Different paradigms are not only incompatible but also incommensurable with each other because they are based on distinct problematiques and concepts. What makes scientific advances revolutionary rather than cumulative is this incommensurability of distinct paradigms. In this respect, if we think of macroprudential ideas as a new paradigm of financial governance, macroprudential ideas are not only incompatible but also incommensurable with the policy paradigm that had dominated financial governance before the 2008 crisis, that is, microprudential ideas.

Despite the discursive articulation between macroprudential ideas and paradigm shifts, most proponents of macroprudential regulation are more likely to observe complementarity rather than incommensurability between microprudential and macroprudential regulations. It is frequently said that macroprudential regulation supplements microprudential regulation because the latter is insufficient to maintain financial stability. For instance, according to 
the G20's Working Group 1, the 2008 crisis highlighted "the need for regulators, supervisors, and central bankers to supplement strong microprudential regulation with a macroprudential overlay" (Helleiner 2014, 101; emphasis added). In a similar vein, the IMF $(2001,3)$ also views macroprudential regulation as "a complement to microprudential policy ... no substitute for sound policies more broadly, including, in particular, strong prudential regulation and supervision, and sound macroeconomic policy" (emphasis added). Even Andrew Baker (2013b), who has strongly argued that macroprudential ideas have induced a paradigm shift in global financial governance, also acknowledges that macroprudential ideas do not completely nullify microprudential regulation because the need for macroprudential regulation is based on the fact that microprudential regulation is necessary but inadequate to maintain financial stability. Therefore, in the words of Baker (2013b, 427), "macroprudential approaches overlay, rather than replace, microprudential approaches in their entirety."

Given that at the heart of the notion of a paradigm shift is the incommensurability thesis, it is difficult to interpret the introduction of macroprudential regulation as a paradigm shift in financial governance, as even proponents of macroprudential regulation stress its supplemental nature to existing microprudential regulation. In this regard, the concept of a paradigm shift can be used only as a rhetorical device, not an analytical framework, in explaining the impact of macroprudential ideas on global financial governance. What can be more appropriately employed as an analytical framework in understanding the meaning of macroprudential ideas in global financial governance is Lakatos's conception of a "scientific research program." According to Lakatos, research programs consist of inviolable hard-core assumptions and a protective belt of auxiliary hypotheses. When anomalies are identified, the reaction of scientists is to protect the hard-core assumptions of the research program by developing auxiliary hypotheses to explain anomalies. Using Lakatos's terms, this paper argues that the introduction of macroprudential ideas into global financial governance can be seen as enhancing the protective belt of auxiliary hypotheses used to explain a newly identified anomaly, that is, systemic risk.

In this regard, the macroprudential turn in global financial governance after the 2008 crisis can be better conceptualized as an "auxiliary change" that indicates an incremental change by developing auxiliary hypotheses while maintaining the hard-core assumptions of the existing policy paradigm, as opposed to a paradigm shift that includes a change in hard-core assumptions. The hard-core assumptions of the financial governance paradigm are the 
ontological and epistemological assumptions that stipulate what entities constitute financial markets and how actors understand the financial world surrounding them and, thus, form their expectations, thereby defining the boundaries of feasibility within which policy measures are formulated. As discussed below, macroprudential ideas introduce auxiliary hypotheses, such as a fallacy of composition and bounded rationality, while leaving largely unchanged the core ontological and epistemological assumptions of the orthodox paradigm.

\section{ONTOLOGY AND EPISTEMOLOGY OF MACROPRUDENTIAL IDEAS}

Essentially, the ontology and epistemology of financial governance can be distinguished dichotomously. First, there are two distinct ontological assumptions about financial governance: individualism and social holism. A key distinction between individualism and social holism lies in their different notions of the status of collective entities. Individualistic ontology assumes that there are no independent entities other than individuals and, thus, sees collective entities as by-products of the interactions of individuals. In contrast, holistic ontology assumes that collective entities are ontologically independent, as the properties of collective entities are not identical or reducible to those of individuals (List and Spiekermann 2013). These different ontological assumptions are strongly related to the primary scale of analysis of financial governance; that is, whether the object of financial regulation should be the behavior of individual actors within the system or the structure of the financial system as a whole (Seabrooke and Tsingou 2014).

Second, the epistemology of financial governance is concerned with understanding how market actors perceive the world around them to make decisions. It can also be distinguished by way of a dichotomy: the rationalistic perspective versus the sociological perspective. The rationalistic perspective assumes that market actors can form and revise the rational expectations of their behavior with calculable probabilities by exploiting all relevant information. In contrast, the sociological perspective regards uncertainty as a key factor that makes it impossible for market actors to calculate the expected outcomes of their behavior and views market actors as embedded in social institutions and conventions on which they rely to address uncertainty and make decisions (Katzenstein and Nelson 2013). 
Efforts to establish international standards and codes following the 1997 Asian crisis relied on microprudential regulation based on the idea that "greater transparency, more disclosure and more effective risk management" could effectively prevent instability in financial markets. In terms of hard-core assumptions, these microprudential ideas were founded on an individualistic ontology and a rationalistic epistemology; that is, the micro-foundation and rational expectations assumption of new classical economics. For new classical economists, "because aggregate outcomes are only the sum of individual decisions, the aggregate relationships should have no independent existence" (Willes 1981, 89; emphasis original). According to them, as all aggregate outcomes can be reducible to individual decisions, social aggregates have no ontological standing independent of individual actors and, thus, ontological status should only be granted to individuals. In addition, it is also assumed that individual actors can form rational expectations by exploiting all available information. Based on a micro-foundational, individualistic ontology and rational expectation epistemology, microprudential regulation shifted the burden of maintaining financial stability from public authorities to private financial institutions, focusing on ensuring adequate transparency and information for individual market actors to properly calculate risks and thus employ appropriate hedging strategies (Best 2008; Blyth 2013).

Several scholars have argued that what enabled a significant distinction between microprudential and macroprudential ideas was their ontological differences. According to them, the emphasis of macroprudential ideas on the need to identify financial risks holistically rather than individually enables "a shift in policymakers' working ontology," as macroprudential ideas view the aggregate as more than the sum of its individual parts by recognizing "social entities and forces that possess an autonomous standing" (Baker and Widmaier 2015, 376-377; Best 2016, 48). In other words, the emergence of macroprudential ideas focusing on systemic risk is accompanied by a change in the ontological focus of the financial governance paradigm from a micro-level into a macro-level.

The principal conceptual idea informing the primary scale of analysis of macroprudential regulation is the notion of a fallacy of composition that the characteristics of the aggregate could be different from those of the individual constituent parts (Baker 2013a). Although the behaviors of financial institutions are rational from the perspective of each individual, the sum of their behaviors could generate undesirable outcomes for the system as a whole. A fallacy of composition makes it difficult to explain system-level outcomes, such as systemic risk, in terms of individual causation, such as risky behaviors of individual 
institutions. For instance, a financial institution's decision to sell a risky asset can be seen as a prudential act from the perspective of the institution. If other institutions follow this prudential decision, however, the price of the asset would plummet, jeopardizing the entire financial system. Employing the notion of a fallacy of composition, macroprudential ideas argue that the prudential behaviors of individual institutions aimed at reducing their own financial risk could increase systemic risk (Datz 2013).

This fallacy of composition leads to dilemmas of collective action that "occur whenever individuals in interdependent situations face choices in which the maximization of short-term self-interest yields outcomes leaving all participants worse off than feasible alternatives" (Ostorm 1998, 1). The collective action dilemmas of financial markets cannot be resolved through the rational behavior of individual actors because what can be seen as irrational behavior from the perspective of the financial system as a whole is fully rational from the perspectives of individual actors (Gamble 2015). For example, when market panic occurs, such as the subprime crisis of 2008 , all financial market actors desperately need open markets for facilitating the rollover of their short-term debts. From the perspective of individual actors, however, financial institutions facing market panic have strong incentives to withhold their money rather than lend it to others, which could aggravate liquidity shortages and market panic (Bell and Hindmoor 2015). As regulatory authorities focused on the soundness of individual institutions before the financial crash of 2008, no one took responsibility for resolving such collective action dilemmas caused by the fallacy of composition in financial markets (Casey 2015). Macroprudential ideas thus seek to resolve such dilemmas by establishing systemic regulatory authorities, such as the FSOC in the US, the FPC in the UK and the ESRB in the EU, which are mandated to manage systemic risk and provide systemic stability (Lombardi and Moschella 2017).

In sum, for those who argue for a paradigm shift in global financial governance, the key conceptual foundation of macroprudential ideas that induces a paradigm change is "a recognition of the need to avoid fallacies of composition" and this recognition derives from macroprudential ontology which, unlike the individualistic ontology of microprudential ideas, acknowledge that the aggregate is more than the sum of its individual parts and "social entities and forces ... possess an autonomous standing" (Baker and Widmaier 2015, 376377).

The fallacy of composition and collective action dilemmas, however, are not incompatible with individualistic ontology. The systemic risk, on which macroprudential ideas focus, results from the uncoordinated behavior of 
individual institutions, not some properties of collective entities. The core problem is that the objective of individual behaviors is not always the same as the outcome of the interactions of those behaviors. In other words, the sum of individual prudential behaviors does not equal systemic stability. While macroprudential ideas recognize that system-level stability differs from individual-level stability, they do not acknowledge any collective entity that is ontologically independent of individual actors. In this respect, macroprudential ideas do not reject the individualistic ontology of microprudential ideas. Rather, the changing focus of macroprudential ideas on the system rather than individual institutions does not result from their holistic ontology but from their causal-explanatory holism.

The key distinction between microprudential and macroprudential ideas is not their different ontological assumptions but their different causal-explanatory assumptions. As List and Spiekermann (2013) have acutely observed, we should distinguish ontological assumptions from causal-explanatory ones. Individualistic ontology is not the same as causal-explanatory individualism: the former is an ontological assumption that social aggregates have no ontological standing independent of individual actors, and the latter is a causal-explanatory assumption that views the causal relations of social phenomena as identical to individual-level causal relations. This distinction between ontological and causal-explanatory assumptions is important because individualistic ontology is compatible with causal-explanatory holism, which claims that social phenomena cannot be fully explained in terms of individual-level causal relations. The notion of a fallacy of composition does not assume any collective entity that has an autonomous ontological standing. Rather, it is based on causal-explanatory holism that stresses that aggregate outcomes are not identical to the sum of individual outcomes and, thus, cannot be fully explained in terms of individuallevel causations.

In sum, while both individualistic ontology and causation are incorporated into microprudential ideas, macroprudential ideas reconcile individual ontology with holistic causation by adopting the notion of a fallacy of composition. Macroprudential ideas enable policymakers and regulators to focus on systemic risk not by inducing a shift in their working ontology, but by indicating the limitation of the causal-explanatory individualism of microprudential ideas in explaining financial instability and by introducing causal-explanatory holism into global financial governance.

In addition, macroprudential ideas are not incompatible with rationalistic epistemology. Rather, the rational assumption is a core part of the macroprudential explanation of systemic instability. Systemic risk is seen 
as caused mainly by the fact that, due to the fallacy of composition, "actions that are individually rational for each market participant may lead to an inefficient outcome overall" (Morris and Shin 2008, 232; emphasis added). Macroprudential regulation is necessary to maintain financial stability not because financial market actors are irrational but because individual rationality is different from collective rationality. Of course, there is an epistemological difference between microprudential and macroprudential ideas. Macroprudentialists regard market actors as "agents with less than idealized rationality" because of their myopia and herd behavior (Tucker 2011, 3-4). Unlike microprudential ideas, macroprudential ideas do not take for granted the comprehensive rationality of market actors in that macroprudentialism views individual actors as unable to precisely calculate the long-term and collective effects of their own decisions. However, they do not abandon the rationalistic perspective but endorse a more limited version of rationality, that is, "bounded rationality," which "takes into account the cognitive limitations of decision makers." Bounded rational actors are intentionally rational, but their rationality sometimes fails because of "a mismatch between decision-making environment and the choices of the decision maker" (Jones 1999, 297-299). Although the bounded rationalistic epistemology of macroprudential ideas is not the same as the comprehensive rationalistic one of microprudential ideas, both can be viewed as members of "a family of rationality models" (Ostrom 1998, 3).

Macroprudential ideas have introduced "the system" as the primary scale of analysis and regulatory rules. However, they do not reject the ontology and epistemology of microprudential ideas; rather, they enhance "the protective belt of auxiliary hypotheses" by introducing the concepts of a fallacy of composition and bounded rationality into the financial governance paradigm while maintaining individual ontology and rationalistic epistemology in a broad sense. Because the ontology and epistemology of policy paradigms are their hard-core assumptions, a paradigm change in financial governance must be explained in terms of ontological and epistemological changes. In this respect, macroprudential ideas are more likely to protect, rather than change, an orthodox financial governance paradigm by adding auxiliary hypotheses to the existing paradigm to explain a newly identified anomaly, that is, systemic risk.

\section{THE SOCIAL CONSTRUCTIVIST ALTERNATIVE}

Whether microprudential or macroprudential, regulatory ideas focusing on risk 
management do not sufficiently take into account the social and intersubjective dimensions of financial markets because their hard-core assumptions of financial markets - individualistic ontology and rationalistic epistemology - do not allow them to recognize this social, intersubjective character of financial markets. In this respect, what are diametrically opposed to microprudential ideas in terms of ontology and epistemology are not macroprudential ideas, but what can be called "social constructivist ideas," which are based on completely different hard-core assumptions from those of prudential ideas-specifically, sociological ontology and epistemology. The essence of constructivism is its ontological recognition of social or institutional facts (Hay 2016; Pouliot 2004). Social facts, which are distinguished from natural or brute facts, exist only through collective intentionality and human agreement (Searle 1995). Constructivist ideas reject individual ontology in that they accept the ontological standing of social facts. By stressing the fact that individual actors interpret the social environment surrounding them through established social facts, they also endorse sociological epistemology. The sociological ontology and epistemology lead to different policy principles for maintaining financial stability that stress constitutive, rather than regulative, rules.

The constructivist understanding of financial markets regards financial actors as social, rather than individually rational, actors embedded in socially constructed institutions and treats financial assets as institutional objects constituted by social conventions or intersubjective understandings (Mugge and Perry 2014). Whether they are comprehensive or bounded, rationalistic approaches are concerned with calculable risk. In contrast, social constructivist approaches regard financial markets as being suffused with uncertainties (Katzenstein and Nelson 2013). ${ }^{2}$ Under a constructivist perspective, expectations of market actors are more likely to be socially constructed than rationally calculated because of the uncertainty facing markets. Due to uncertainty prevalent in the market, in the words of Keynes $(1937,214)$, "there is no scientific basis on which to form any calculable probability whatever." In the context of uncertainty, it is impossible to make a decision with a precise calculation about the probabilities of payoffs and the size of those payoffs. In order not to be paralyzed by indecision, however, financial market actors need to be convinced that their decisions are appropriate to yield expected returns. Social conventions instill confidence in the decision making of financial actors under uncertainty and thus help them not to be paralyzed by uncertainty. In this regard, financial

\footnotetext{
${ }^{2}$ Uncertainty can be distinguished from risk. While risk is a measurable probability, uncertainty cannot be measured and calculated because of its high degree of uniqueness (Knight 1946).
} 
markets are, in the words of Katzenstein and Nelson (2013, 1108), "riddled with uncertainty and stabilized by conventions." In other words, facing uncertainty that renders market actors unable to precisely calculate the probabilistic payoffs of their actions, the decision making of market actors is more likely to rely on prevailing intersubjective conventions than their own rational calculations (Katzenstein and Nelson 2013; Nelson and Katzenstein 2014). ${ }^{3}$

Social conventions are different from explicit agreements or formal rules. Rather, these conventions are common knowledge on which individual actors rely to construct their expectations about the behavior of other actors and the environments surrounding them (Culpepper 2008). Simplifying uncertain situations, social conventions enable financial actors to "impose classification schemas on the world" and inform them of "what decisions are reasonable" (Katzenstein and Nelson 2013, 1107-1108). The common knowledge of financial markets derives from the intersubjective understandings of how financial markets that are socially shared by market actors work. The intersubjective understandings are socially, rather than individually, constituted, since in order for a set of ideas to be intersubjective, they need to be socially diffused and shared. A financial theory or discourse achieves the status of social convention when it becomes the only language in which public and private actors in the market may "credibly speak" (Hall 2008, 183). These intersubjective understandings are ontologically independent of individual actors since they are not merely the collection of subjective ideas of individual actors; rather, the subjective ideas of individual actors are more likely to be constituted by social conventions. As Hall (2009, 453-455) has put it, "market actors do not act on the basis of 'rational expectations,' but on the basis of 'intersubjective expectations." Stable transactions among financial market actors are made possible not by their own rational expectations independent of social conventions, but by intersubjective expectations instilled by social conventions. Financial market actors look to collectively formed understandings in order to classify financial assets, form their expectations, and settle on their decisions. In that respect, the decision making of financial actors is unavoidably marked by a social process, rather than one that is individually rational (Baker and Widmaier 2014; Best 2008).

The social conventions of financial markets take various forms in terms of

${ }^{3}$ It is also important to note that uncertainty is different from complexity. For example, the game of chess is complex but not uncertain (Katzenstein and Nelson 2013). Macroprudential ideas stress the complexity of financial markets because individual institutions cannot precisely identify and manage systemic risk. In contrast, social constructivist ideas are centered on uncertainty, which leads financial actors to rely on social conventions. 
their degree of materiality and robustness: they can be common understandings implicitly shared by financial actors, embedded in explicit economic models and formulations, or codified and endorsed by formal rules and standards (Mugee and Perry 2014; Nelson and Katzenstein 2014). Macroprudential ideas do not sufficiently address this social basis of financial markets. For instance, structured financial products such as mortgage-backed securities (MBSs) and collateralized debt obligations (CDOs), which significantly contributed to the 2008 crash, were so complex and opaque that their intrinsic values could not be correctly calculated and priced in the market. When the prospects of markets became murkier, the complex and obscure nature of the products caused demand for them to evaporate and their prices to plummet (Crotty and Epstein 2009; Helleiner 2011). What enabled economic transactions of such complex and opaque products were intersubjective understandings of financial markets. The process of securitization had been buttressed by both implicit and explicit intersubjective understandings. First, "new era stories" were implicit beliefs shared by investors, homeowners, and regulators that home prices would continue to increase, which made many ordinary homeowners active participants in financial markets, thereby generating a growing demand for MBSs and CDOs (Best 2009). Second, "Value-at-Risk" (VaR) was an explicit risk management model widely used by financial institutions and officially endorsed by regulators that assumed that the future could be rendered probabilistically calculable based on past data on the distribution of profits and losses (Nelson and Katzenstein 2014, 372-379).

In particular, VaR was not just an apolitical technique that financial actors employed to evaluate their risk exposure; rather, it was an authoritative social practice that constituted financial transactions among financial actors (Lockwood 2015). Financial actors socially emulated authoritative economic models and formulations such as the VaR model, thereby instilling a common understanding into financial markets and enabling transactions in such opaque products as MBSs and CDOs. Systemic risk results not only from a fallacy of composition, as macroprudential ideas stress, but also from the convergence of social conventions. Valuation techniques such as VaR were performative; they did not just estimate financial values and risks, but also constituted financial markets as financial actors relied on them to make decisions (Stellinga and Mugge 2017). Neoliberal ideas assumed that market competition and deregulation would result in varied risk management practices, thereby diversifying financial risk across the entire financial system and enhancing financial stability. However, risk evaluations were more likely to converge rather than diverge among financial institutions, exacerbating the boom-and-bust financial cycle (Casey 2015). This 
convergence of risk evaluations among financial actors resulted from the social diffusion of the VaR model, which acted as a technical convention on which actors relied to form their expectations and make decisions. In this respect, the VaR model, in the words of MacKenzie (2006, 12), "did more than analyze markets; it altered them. It was an 'engine' ... an active force transforming its environment, not a camera passively recording it."

In addition, although systemic risk is newly recognized as a core problem in maintaining financial stability, macroprudential ideas still conceptualize the problem of financial markets in terms of risk management. Macroprudential ideas do not agree with the underlying assumption of microprudential regulation that all financial risks can be effectively managed by appeal to individual market actors. Whether they focus on individual or systemic risk, however, the policy goal of both microprudential and macroprudential regulations is risk management based on the assumption that economic indeterminacy can be transformed into probabilistic calculations by enhancing the capacity of financial institutions or regulators to gather and process information. As Best (2010, 38-40) puts it, macroprudential solutions to newly identified systemic risk are not unfamiliar in that they just require "more sophisticated mechanisms for measuring this more complex form of risk as well as more information with which to make these new risk calculations."

While both macro- and microprudential ideas aim to regulate individual financial institutions or the financial system as whole to manage individual or systemic risk, the implication of a constructivist understanding of financial markets places emphasis on constitutive, rather than regulative, rules. According to Searle (1995, 27-28), the purpose of regulative rules is to "regulate antecedently existing activities," whereas constitutive rules aim to "create the very possibility of certain activities." For instance, "the rules of chess do not regulate an antecedently existing activity. ... Rather, the rules of chess create the very possibility of playing chess." In contrast to the regulative rules of macroprudential ideas, which seek to control the excessive, uncoordinated behaviors of individual financial institutions, the constitutive rules of constructivist ideas recognize the social basis of financial markets and stress the social construction of rationality by affecting intersubjective understandings of financial markets about what constitutes legitimately rational behaviors. For example, the global financial crisis of 2008 can be interpreted as the breakdown of existing constitutive rules that had enabled the transactions of structured financial products such as MBSs and CDOs. The panic and paralysis that overwhelmed financial markets and made financial actors unwilling to transact with one another during the crisis were caused by the collapse 
of existing intersubjective understandings or the social conventions that constituted the socially-shared rationality of financial market actors. Whether it is microprudential or macroprudential, therefore, regulation is not the only problem; the fundamental problem for maintaining financial stability is how to constitute financial markets (Sinclair 2009).

Unlike macroprudential ideas, social constructivist ideas are founded on completely different ontological and epistemological assumptions from those of microprudential ideas. Recognizing the social, intersubjective dimensions of financial markets, they endorse sociological ontology and epistemology. In this regard, social constructivist ideas can lead to a fundamental change not only in the primary scale of analysis, from individual institutions to the system as a whole-which macroprudential ideas focus on-but also in the problematique of financial governance itself, from how to regulate financial markets to how to construct them. The paradigmatic differences between microprudential, macroprudential, and social constructivist ideas of financial governance and their policy implications discussed thus far are summarized in Table 1.

Table 1. Policy Paradigms of Financial Governance

\begin{tabular}{|c|c|c|c|c|}
\hline & Ontology & Epistemology & Causation & Policy Implications \\
\hline $\begin{array}{l}\text { Microprudential } \\
\text { Ideas }\end{array}$ & Individualism & $\begin{array}{l}\text { Rationalistic } \\
\text { perspective }\end{array}$ & $\begin{array}{l}\text { Causal-explanatory } \\
\text { individualism }\end{array}$ & $\begin{array}{c}\text { Microprudential } \\
\text { regulative rules } \\
\text { to manage individual risk }\end{array}$ \\
\hline $\begin{array}{l}\text { Macroprudential } \\
\text { Ideas }\end{array}$ & Individualism & $\begin{array}{l}\text { Bounded } \\
\text { rationalistic } \\
\text { perspective }\end{array}$ & $\begin{array}{c}\text { Causal-explanatory } \\
\text { holism }\end{array}$ & $\begin{array}{l}\text { Macroprudential } \\
\text { regulative rules } \\
\text { to manage systemic risk }\end{array}$ \\
\hline $\begin{array}{c}\text { Social } \\
\text { Constructivist Ideas }\end{array}$ & Social holism & $\begin{array}{l}\text { Sociological } \\
\text { perspective }\end{array}$ & $\begin{array}{c}\text { Causal-explanatory } \\
\text { holism }\end{array}$ & $\begin{array}{l}\text { Social constitutive rules } \\
\text { to construct markets }\end{array}$ \\
\hline
\end{tabular}

\section{CONCLUSION}

Many view the global financial crisis of 2008 as being caused by, in the words of Seabrooke and Tsingou (2010, 313), "an over-supply of financial innovation and an under-supply of financial regulation," fostering a search for new regulatory measures. As a result, following the 2008 financial crisis, macroprudential ideas have become the center of the financial governance agenda by providing not only an interpretive framework for diagnosing the crisis, but also an institutional 
blueprint for financial reform. As Mackintosh $(2015,4)$ put it, "we should not underestimate the significance of the "relatively radical intellectual change' that the macroprudential narrative shift represents," since before the 2008 crisis, financial regulatory communities focused only on the financial risk of individual institutions and largely ignored the systemic risk of financial markets.

However, macroprudential ideas are not radical enough to induce a fundamental paradigm shift in financial governance. Rather, they have developed the protective belt of auxiliary hypotheses for dealing with such newly identified anomalies as systemic risk by employing notions of a fallacy of composition and bounded rationality. Macroprudential regulation is the result of a compromise that straddles the pro-market orthodoxy of global financial governance before the 2008 crisis and an increasing demand for public regulation on financial markets after the crisis (Ban et al. 2016). In this respect, the macroprudential turn in financial governance can be seen as an "auxiliary change," not a paradigm change. This auxiliary change in the financial governance paradigm partly explains the limited nature of change in financial governance after the 2008 crisis; a change understood as "more of a status quo event than a transformative one" (Helleiner 2014, 2) or "a juncture of bounded transformation" (Onis and Guven 2011, 470).

In terms of the policy implications of this turn, macroprudential regulation could fill the regulatory loophole of global financial governance by giving public authorities a new mandate for managing the endogenous, systemic risk of financial markets. However, macroprudential ideas not only help to find the blind spot of financial regulation unidentified by microprudential ideas, but also hinder a more fundamental change of financial governance (Kessler 2012). In a more fundamental sense, not just financial stability but the financial system itself should be seen as a public good that acts as the infrastructure of the whole economy. In this respect, the financial system needs to be constructed by public authorities rather than private organizations. Whether they are microprudential or macroprudential, however, regulatory approaches to the global financial system regard financial institutions foremost as private business organizations whose ultimate purpose is profit generation, and the goal of public authority as regulating the excessive business strategies of financial institutions that could jeopardize financial stability (Mugge 2014). Macroprudential regulation that focuses on systemic risk management while maintaining the expansion and innovation of financial markets would contribute to reinforcing, rather than transforming, the existing financial system by reducing the volatility of financial markets without changing the expansive and innovative characteristics of the current financial system (Casey 2015). 
In this regard, the concentrated efforts to find new regulatory measures tend to obscure a more fundamental aspect of financial governance on which social constructivist ideas place strong emphasis. Founded on sociological ontology and epistemology, constructivist ideas help us recognize the social basis of financial markets and the importance of constitutive rules of financial governance in managing financial markets, which could lead to a genuine paradigm change in global financial governance.

\section{REFERENCES}

Baker, Andrew. 2010. "Restraining Regulatory Capture? Anglo-America, Crisis Politics and Trajectories of Change in Global Financial Governance." International Affairs 86(3), 647-663.

2013a. "The New Political Economy of the Macroprudential Ideational Shift." New Political Economy 18(1), 112-139.

2013b. "The Gradual Transformations? The Incremental Dynamics of Macroprudential Regulation." Regulation and Governance 7(4), 417434.

. 2015. "Varieties of Economic Crisis, Varieties of Ideational Change: How and Why Financial Regulation and Macroeconomic Policy Differ." New Political Economy 20(3), 342-366.

Baker, Andrew, and Wesley Widmaier. 2015. "Macroprudential Ideas and Contested Social Purpose: A Response to Terrence Casey." British Journal of Politics and International Relations 17(2), 371-380.

Ban, Cornel, Leonard Seabrooke, and Sarah Freitas. 2016. "Grey Matter in Shadow Banking: International Organizations and Expert Strategies in Global Financial Governance." Review of International Political Economy 23(6), 1001-1033.

Bell, Stephen, and Andrew Hindmoor. 2015. "Masters of the Universe but Slaves of the Market: Bankers and the Great Financial Meltdown." British Journal of Politics and International Relations 17(1), 1-22.

Best, Jacqueline. 2008. "Ambiguity, Uncertainty, and Risk: Rethinking Indeterminacy." International Political Sociology 2(4), 355-374. 2009. "How to Make a Bubble: Toward a Cultural Political Economy of the Financial Crisis." International Political Sociology 3(4), 461-465. 2010. "The Limits of Financial Risk Management: Or What We Didn't Learn from the Asian Crisis." New Political Economy 15(1), 29-49. . 2016. "When Crises Are Failures: Contested Metrics in International 
Finance and Development." International Political Sociology 10(1), 3955 .

Blyth, Mark. 2013. "Paradigms and Paradox: The Politics of Economic Ideas in Two Moments of Crisis." Governance: An International Journal of Policy, Administration, and Institutions 26(2), 197-215.

Casey, Terrence. 2015. "How Macroprudential Financial Regulation Can Save Neoliberalism." British Journal of Politics and International Relations 17(2), 351-370.

Crokett, Andrew. 2000. "Marrying the Micro- and Macro-Prudential Dimensions of Financial Stability." Remarks at the $11^{\text {th }}$ International Conference of Banking Supervisors (September 20-21). Accessed at https://www.bis.org/speeches/spooog21.htm (September 10, 2017).

Crotty, James, and Gerald Epstein. 2009. "Avoiding Another Meltdown." Challenge 52(1), 5-26.

Culpepper, Pepper D. 2008. "The Politics of Common Knowledge: Ideas and Institutional Change in Wage Bargaining." International Organization 62(1), 1-33.

Datz, Giselle. 2013. "The Narrative of Complexity in the Crisis of Finance: Epistemological Challenge and Macroprudential Policy Response.” New Political Economy 18(4), 459-479.

Financial Stability Forum (FSF). 2008. Report of Financial Stability Forum on Enhancing Market and Institutional Resilience. Basel: Financial Stability Forum.

Frenkel, Roberto, and Martin Rapetti. 2009. "A Developing Country View of the Current Global Crisis: What Should Not Be Forgotten and What Should Be Done." Cambridge Journal of Economics 33(4), 685-702.

Gamble, Andrew. 2015. "Slaves to the Market: A Response to Bell and Hindmoor." British Journal of Politics and International Relations 17(1), 27-30.

Haldane, Andrew G. 2009. "Small Lessons from a Big Crisis." Speech at the Federal Reserve Bank of Chicago $45^{\text {th }}$ Annual Conference (May 8). Accessed at http://www.bankofengland.co.uk/archive/Documents/ historicpubs/speeches/2009/speech397.pdf (September 1, 2016).

Hall, Peter A. 1993. "Policy Paradigms, Social Learning, and the State: The Case of Economic Policymaking in Britain." Comparative Politics 25(3), 275-296.

Hall, Rodney Bruce. 2008. Central Banking as Global Governance. New York, NY: Cambridge University Press.

. 2009. "Intersubjective Expectations and Performativity in Global 
Financial Governance.” International Political Sociology 3(4), 453-457. Harnay, Sophie, and Laurence Scialom. 2016. "The Influence of the Economic Approaches to Regulation on Banking Regulations: A Short History of Banking Regulations." Cambridge Journal of Economics 40(2), 401426.

Hay, Colin. 2016. "Good in a Crisis: The Ontological Institutionalism of Social Constructivism." New Political Economy 21(6), 520-535.

Helleiner, Eric. 2011. "Understanding the 2007-2008 Global Financial Crisis: Lessons for Scholars of International Political Economy." Annual Review of Political Science 14, 67-87. 2014. The Status Quo Crisis: Global Financial Governance after the 2008 Meltdown. Oxford, UK: Oxford University Press.

International Monetary Fund (IMF). 2001. "Macroprudential Policy: An Organizing Framework." Policy Paper (March 14). Accessed at https:// www.imf.org/external/np/pp/eng/2011/o31411.pdf (August 8, 2016).

Jones, Bryan D. 1999. "Bounded Rationality." Annual Review of Political Science 2, 297-321.

Katzenstein, Peter J., and Stephen C. Nelson. 2013. "Reading the Right Signals and Reading the Signals Right: IPE and the Financial Crisis of 2008." Review of International Political Economy 20(5), 1101-1131.

Kessler, Oliver. 2012. "Sleeping with the Enemy? On Hayek, Constructivist Thought, and the Current Economic Crisis." Review of International Studies 38(2), 275-299.

Keynes, John Maynard. 1937. "The General Theory of Employment." Quarterly Journal of Economics 51(2), 209-233.

Knight, Frank. 1946. Risk, Uncertainty and Profit. Boston, MA: Houghton Mifflin Company.

Kuhn, Thomas. 1962. The Structure of Scientific Revolutions. Chicago, IL: University of Chicago Press.

Lakatos, Imre. 1970. "Falsification and the Methodology of Scientific Research Programmes." In Imre Lakatos and Alan Musgrave eds., Criticism and the Growth of Knowledge, Cambridge, UK: Cambridge University Press, 91-195.

List, Christian, and Kai Spiekermann. 2013. "Methodological Individualism and Holism in Political Science: A Reconciliation.” American Political Science Review 107(4), 629-643.

Lockwood, Erin. 2015. "Predicting the Unpredictable: Value-at-Risk, Performativity, and the Politics of Financial Uncertainty." Review of International Political Economy 22(4), 719-756. 
Lombardi, Demenico, and Manuela Moschella. 2017. "The Symbolic Politics of Delegation: Macroprudential Policy and Independent Regulatory Authorities." New Political Economy 22(1), 92-108.

MacKenzie, Donald. 2006. An Engine, Not a Camera: How Financial Models Shape Markets. Cambridge, MA: The MIT Press.

Mackintosh, Stuart P. M. 2014. "Crises and Paradigm Shift." Political Quarterly 85(4), 406-412.

2015. "Crises and Paradigm Shift: A Response to Critics." Political Quarterly 86(1), 3-6.

Morris, Stephen, and Hyun Song Shin. 2008. "Financial Regulation in a System Context." Brookings Papers on Economic Activity (Fall), 229274.

Mugge, Daniel. 2014. "Policy Inertia and the Persistence of Systemic Fragility." Political Quarterly 85(4), 413-416.

Mugge, Daniel, and James Perry. 2014. "The Flaws of Fragmented Financial Standard Setting: Why Substantive Economic Debates Matter for the Architecture of Global Governance." Politics and Society 42(2), 194222.

Nelson Stephen C., and Peter J. Katzenstein. 2014. "Uncertainty, Risk and the Financial Crisis of 2008." International Organization 68(2), 361-392.

Onis, Ziya, and Ali Burak Guven. 2011. "The Global Economic Crisis and the Future of Neoliberal Globalization: Rupture versus Continuity." Global Governance 17(4), 469-488.

Ostrom, Elinor. 1998. "A Behavioral Approach to the Rational Choice Theory of Collective Action." American Political Science Review 92(1), 1-22.

Pouliot, Vincent. 2004. "The Essence of Constructivism." Journal of International Relations and Development 7(3), 319-336.

Seabrooke, Leonard, and Eleni Tsingou. 2010. "Responding to the Global Credit Crisis: The Politics of Financial Reform." British Journal of Politics and International Studies 12(2), 313-323. . 2014. "Distinctions, Affiliations, and Professional Knowledge in Financial Reform Expert Groups." Journal of European Public Policy 21(3), 389-407.

Searle, John. 1995. The Construction of Social Reality. New York, NY: The Free Press.

Sinclair, Timothy J. 2009. "Let's Get It Right This Time! Why Regulation Will Not Solve or Prevent Global Financial Crises." International Political Sociology 3(4), 450-453.

Stellinga, Bart, and Daniel Mugge. 2017. "The Regulator's Conundrum. How 
Market Reflexivity Limits Fundamental Financial Reform.” Review of International Political Economy 24(3), 393-423.

Tucker, Paul. 2011. "Reforming Finance: Are We Being Radical Enough?" Remarks at Clare Distinguished Lecture in Economics, Cambridge (February 18). Accessed at http://www.bankofengland.co.uk/archive/ Documents/historicpubs/speeches/2011/speech477.pdf (August 7, 2016).

Wade, Robert. 2007. “A New Global Financial Architecture?” New Left Review $46,113-129$.

. 2008. "The First-World Debt Crisis of 2007-2010 in Global Perspective." Challenge 51(4), 23-54.

Willes, Mark H. 1981. "Rational Expectations as Counter-Revolution." In Daniel Bell and Irving Kristol eds., The Crisis in Economic Theory, New York, NY: Basic Books, 81-97.

[Received Jul 9, 2018; Revised Aug 1, 2018; Accepted Aug 30, 2018] 